\title{
Polyphenol-Rich Foods in the Mediterranean Diet are Associated with Better Cognitive Function in Elderly Subjects at High Cardiovascular Risk
}

\author{
Cinta Valls-Pedret ${ }^{\mathrm{a}, \mathrm{b}}$, Rosa Maria Lamuela-Raventós $\mathrm{s}^{\mathrm{b}, \mathrm{c}, \mathrm{d}}$, Alexander Medina-Remón ${ }^{\mathrm{b}, \mathrm{c}, \mathrm{d}}$, \\ Melibea Quintana $^{\mathrm{a}}$, Dolores Corella ${ }^{\mathrm{b}, \mathrm{e}}$, Xavier Pintó $^{\mathrm{d}, \mathrm{f}}$, Miguel Ángel Martínez-González ${ }^{\mathrm{d}, \mathrm{g}}$, \\ Ramon Estruch ${ }^{\mathrm{b}, \mathrm{h}}$ and Emilio Ros ${ }^{\mathrm{a}, \mathrm{b}, *}$ \\ ${ }^{\mathrm{a}}$ Lipid Clinic, Endocrinology and Nutrition Service, Institut d'Investigacions Biomèdiques August Pi i Sunyer \\ (IDIBAPS), Hospital Clínic, Barcelona, Spain \\ ${ }^{\mathrm{b}}$ CIBER Fisiopatología de la Obesidad y Nutrición (CIBERobn), Instituto de Salud Carlos III (ISCIII), Spain \\ ${ }^{\mathrm{c} N u t r i t i o n}$ and Food Science Department, XaRTA, INSA, Pharmacy School, University of Barcelona, Barcelona, \\ Spain \\ ${ }^{\mathrm{d}}$ RETIC RD06/0045, Instituto de Salud Carlos III (ISCIII), Spain \\ ${ }^{\mathrm{e}}$ Department of Preventive Medicine and Public Health, School of Medicine, University of Valencia, Valencia, Spain \\ ${ }^{\mathrm{f}}$ Unitat de Lipids i Risc Vascular, Servei de Medicina Interna, Hospital Universitari de Bellvitge, Barcelona, Spain \\ ${ }^{\mathrm{g}}$ Department of Preventive Medicine and Public Health, School of Medicine, University of Navarra, Pamplona, \\ Spain \\ ${ }^{\mathrm{h}}$ Department of Internal Medicine, IDIBAPS, Hospital Clínic, Barcelona, Spain
}

Handling Associate Editor: Vincenza Frisardi

Accepted 3 January 2012

\begin{abstract}
Brain oxidative processes play a major role in age-related cognitive decline, thus consumption of antioxidant-rich foods might help preserve cognition. Our aim was to assess whether consumption of antioxidant-rich foods in the Mediterranean diet relates to cognitive function in the elderly. In asymptomatic subjects at high cardiovascular risk $(n=447 ; 52 \%$ women; age 55-80 y) enrolled in the PREDIMED study, a primary prevention dietary-intervention trial, we assessed food intake and cardiovascular risk profile, determined apolipoprotein E genotype, and used neuropsychological tests to evaluate cognitive function. We also measured urinary polyphenols as an objective biomarker of intake. Associations between energy-adjusted food consumption, urinary polyphenols, and cognitive scores were assessed by multiple linear regression models adjusted for potential confounders. Consumption of some foods was independently related to better cognitive function. The specific associations [regression coefficients (95\% confidence intervals)] were: total olive oil with immediate verbal memory [0.755 (0.151-1.358)]; virgin olive oil and coffee with delayed verbal memory [0.163 (0.010-0.316) and 0.294 (0.055-0.534), respectively]; walnuts with working memory [1.191 (0.061-2.322)]; and wine with Mini-Mental State Examination scores [0.252 (0.006-0.496)]. Urinary polyphenols were associated with better scores in immediate verbal memory [1.208 (0.236-2.180)]. Increased consumption of
\end{abstract}

\footnotetext{
*Correspondence to: Emilio Ros, Lipid Clinic, Endocrinology and Nutrition Service, Hospital Clínic. Villarroel 170, 08036 Barcelona, Spain. Tel.: +34 932279383; Fax: +34 934537829; E-mail: eros@clinic.ub.es.
} 
antioxidant-rich foods in general and of polyphenols in particular is associated with better cognitive performance in elderly subjects at high cardiovascular risk. The results reinforce the notion that Mediterranean diet components might counteract age-related cognitive decline.

Keywords: Aging, coffee, cognition, Mediterranean diet, nutrition, polyphenols, olive oil, walnuts, wine

\section{INTRODUCTION}

Increased lifespan in developed countries has resulted in a greatly raised frequency of diseases related to aging, such as cardiovascular and neurodegenerative disorders, including Alzheimer's disease (AD), the most common type of dementia [1]. AD is characterized by cognitive deterioration with a progressive impairment of activities of daily living. Cognitive changes, however, are not particular to severe neurodegenerative diseases like $\mathrm{AD}$, as the aging process naturally entails normal age-associated cognitive decline. The cognitive functions that are most frequently affected with aging are memory, especially codification, recall, and working memory, and executive functions that imply information processing speed, divided attention, and planning [2].

Factors recognized to aid in maintaining cognitive performance include years of schooling, professional achievement, social engagement, and physical activity [3]. Such factors are encompassed in the concept of cognitive reserve, described as the brain's capacity to compensate for neuropathological damage in brain aging, making clinical symptoms unobtrusive or even imperceptible [4]. An appealing link hypothesized in recent years is the association between lifestyle habits, particularly food patterns, and cognitive reserve [3, 5]. Epidemiological studies suggest that foods such as fruits, vegetables, fish, and wine and nutrients such as polyunsaturated fatty acids, E and B-vitamins, and antioxidants might protect from age-related cognitive decline, mild cognitive impairment (MCI) and $\mathrm{AD}$ [6-10]

Nutritional epidemiology has evolved beyond nutrients and foods, with increasing recognition of the importance of dietary patterns, in which synergy exists among food constituents, with additive effects on health $[11,12]$. One such pattern is the traditional Mediterranean diet, a reputed model of healthy eating that is characterized by a high consumption of foods and nutrients presumed to be healthy for the brain, such as vegetables, fruits, fish, unsaturated fatty acids, and diverse antioxidants, with moderate intake of alcoholic beverages, mostly wine [13]. Both prospective and clinical studies report that greater adherence to a Mediterranean-type diet is associated with a reduced incidence of coronary heart disease (CHD) [13-15]. Consistently, epidemiological studies point to a reduction in the incidence of and mortality from cardiovascular diseases $[13,15,16]$ and cancer, which results in increased longevity [16]. Importantly, as recently reviewed [17], increasing compliance with Mediterranean-type diets has also been associated with slower cognitive decline [18], a reduction in the incidence of MCI [19], neurodegenerative disorders such as Parkinson's disease [20] and AD [21, 22], and mortality attributable to $\mathrm{AD}[23,24]$.

Oxidative stress and ensuing inflammation are believed to play major roles in the pathogenesis of age-related diseases, including cognitive impairment and AD. They also are ideal targets for nutritional intervention with antioxidants, for which the Mediterranean diet is particularly well suited [25]. Therefore, we evaluated in a cross-sectional study whether consumption of antioxidant-rich foods from the Mediterranean diet was associated with better cognitive performance in a cohort of elderly persons at high risk for CHD living in Spain, a Mediterranean country. In addition, since there is evidence that consumption of flavonoids, a subclass of polyphenols, positively relates to cognitive function [26], we complemented dietary data with urinary polyphenol excretion, an objective biomarker of phenol intake.

\section{METHODS}

\section{Participants and design of the study}

The study population was drawn from the cohort of the PREDIMED (PREvención con DIeta MEDiterránea) study, a clinical trial in asymptomatic persons at high cardiovascular risk testing the Mediterranean diet for outcomes on cardiovascular disease events (http://www.predimed.org; ISRCTN35739639). The design of the PREDIMED study has been described in detail elsewhere [27]. Candidates were community-dwelling men aged 55-80 years and women aged 60-80 years, without prior cardiovascular disease but having a prior diagnosis of diabetes or at least three cardiovascular risk factors, 
namely smoking, hypertension, dyslipidemia, overweight (body mass index $[\mathrm{BMI}] \geq 25 \mathrm{~kg} / \mathrm{m}^{2}$ ), and family history of premature cardiovascular disease ( $\leq 55$ years in men and $\leq 60$ years in women). Other exclusion criteria were any severe chronic illness, alcohol or drug abuse, or BMI $\geq 40 \mathrm{~kg} / \mathrm{m}^{2}$. Participants fulfilling inclusion criteria and not meeting exclusion criteria provided informed consent to a protocol approved by the local review board and underwent various tests, including venipuncture to obtain fasting blood and collection of a spot urine sample.

Anthropometric and blood pressure measurements were performed by standard methods, as previously described [27]. Smoking status was categorized into never, current or past smoking according to selfreports. Physical activity was assessed with the validated Spanish version of the Minnesota questionnaire and expressed in minutes at a given metabolic equivalent (MET-min) per day [28]. Dietary data related to self-selected food intake during the previous year were collected during a face-to-face interview with a single trained dietitian using a validated 137item food-frequency questionnaire (FFQ) [29] and converted to daily intakes. Energy and nutrient intake were calculated from Spanish food composition tables. The apolipoprotein E (APOE) genotype was determined by using the method of Hixson and Vernier [30]. High-sensitivity C-reactive protein (CRP) was measured using an immunoturbidimetric technique. Total polyphenols in spot urine samples were determined with the Folin-Ciocalteu assay after solid phase extraction, together with the creatinine concentration, as described [31]. Total polyphenol excretion was expressed as $\mathrm{mg}$ of gallic acid equivalents (GAE)/g of creatinine. Urinary total polyphenol excretion expressed by 24-h volume is a better biomarker of polyphenol dietary intake than expressed by urinary creatinine normalization. However, when total volume in 24-h is not available, creatinine-corrected urinary total polyphenol excretion may also be a suitable biomarker of total polyphenols in a free-living population [32].

From October 2004 to December 2009, 578 consecutive persons entering the PREDIMED study in the recruiting centre located at Hospital Clínic (Barcelona, Catalonia, Spain) were asked to submit to neuropsychological testing to assess cognitive function. During the screening visit, participants were asked about education years and information about exclusion criteria specific for this substudy was sought, namely depression, as assessed by the Hamilton Depression Rating Scale (participants with a score $>13$ were excluded)
[33], severe cognitive impairment, defined by a score $<25$ in the Mini-Mental State Examination (MMSE) [34], illiteracy, or difficulty in expression or comprehension of Spanish language.

\section{Cognitive assessment}

An experienced neuropsychologist who was blinded to the subjects' diet and cardiovascular risk factors conducted the cognitive examination. The instruments used were the MMSE to assess global cognitive function [34]; the Rey auditory verbal learning test (RAVLT) to rate immediate (sum of words recalled on the five learning trials) and delayed episodic verbal memory [35]; the verbal paired associates test, a subtest of Wechsler Memory Scale (WMS) [36], to evaluate episodic memory performance; the semantic verbal fluency test [37]; the digit span test of the Wechsler Adult Intelligence Scale (WAIS) [38] to assess immediate memory (direct digits) and working memory (reverse order digits); and the Color Trail Test (part I and II) [39] to measure executive function, including attention, visual-motor speed, and cognitive flexibility.

\section{Statistical analyses}

We fitted multiple linear regression models to assess independent associations of demographic, clinical, and dietary variables and urinary polyphenol excretion with neuropsychological test scores. In the first model, with cognitive test scores as dependent variables, we introduced the energy-adjusted intakes of various food groups (cereals, vegetables, fruits, legumes, nuts, meat and meat products, seafood, olive oil, alcohol, and coffee) as independent variables. In the second model we adjusted for age, gender, education years, BMI, current smoking, physical activity, APOE genotype, diabetes, hypertension and hyperlipidemia, and the food groups that were significantly associated with test scores in the first model as potential confounders. Because in addition to questions on intake of total alcohol, olive oil, and nuts, the FFQ used in the study contains specific questions on intake of wine, virgin olive oil (VOO), and walnuts, we constructed additional models where alcohol, olive oil, and nut consumption were replaced by wine and other alcoholic beverages, VOO and common olive oil, and walnuts and other nuts, respectively. In a further model, we entered as independent variable urinary polyphenol excretion alone, to avoid collinearity with other antioxidant-rich food groups, with adjustment for the same variables plus total energy intake. Finally, the logarithmical transformed values 
of urinary polyphenol excretion and serum CRP were entered in a partial correlation adjusted by gender, age and BMI. $p$ values $<0.05$ were considered significant. SPSS software, version 16.0 (SPSS Inc., Chicago, IL) was used for statistical analyses.

\section{RESULTS}

\section{Characteristics of participants}

Figure 1 shows the flow of participants. By study design, there was a high prevalence of cardiovascular risk factors in the 447 participants available for analysis (Table 1).

As shown in Table 2, the self-selected participant's dietary habits reasonably conformed to the traditional Mediterranean food pattern in several aspects, as they recorded high intakes of cereals, vegetables, fruits, fish, and olive oil and moderate intakes of legumes, nuts, and wine. They deviated from the traditional Mediterranean diet, however, because of high intakes of meat and dairy products. The extreme ranges underscore the high between-subject variability of energy and food intake and urinary polyphenol excretion.

\section{Cognitive performance}

Various clinical, demographic and dietary variables were independently associated with the outcomes of neuropsychological tests by multiple linear regression analyses after adjustment for various confounders. The fully adjusted associations are shown in Table 3. Older age, diabetes, and hypertension were associated with lower MMSE scores, while higher education years and higher wine intake were associated with better perfor-

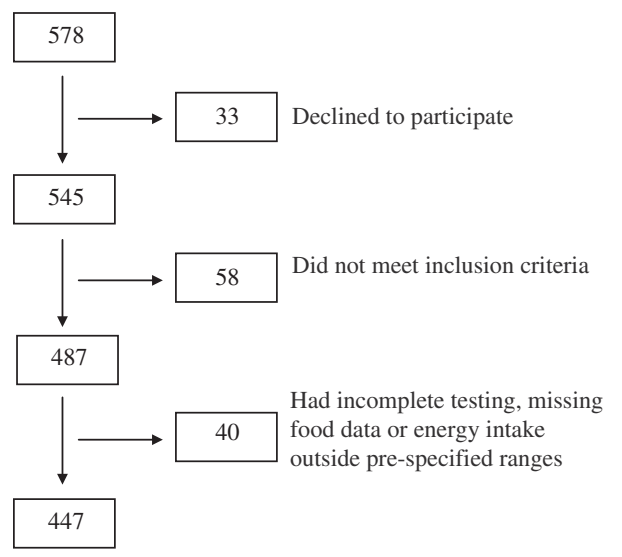

Fig. 1. Flow chart of participants.
Table 1

Socio-demographic and anthropometric characteristics, physical activity, cardiovascular risk factors and APOE genotype of the study population $(n=447)$

\begin{tabular}{lcc}
\hline Variables & Mean or median & Range \\
\hline Age (years) & 66.9 & $(54.7-80.2)$ \\
Women, $n(\%)$ & $233(52.1)$ & \\
Education (years) & 7.18 & $(0-14)$ \\
Body mass index $\left(\mathrm{kg} / \mathrm{m}^{2}\right)$ & 28.5 & $(18.8-36.8)$ \\
Leisure-time physical & & \\
$\quad$ activity (Kcal/d) & $235^{*}$ & $(0-1382)$ \\
Home physical activity $(\mathrm{Kcal} / \mathrm{d})$ & $179 *$ & $(0-1755)$ \\
Energy expenditure & & \\
$\quad$ in physical activity $(\mathrm{MET}-\mathrm{min} / \mathrm{d})$ & $492^{*}$ & $(0-2028)$ \\
Family history of & & \\
$\quad$ early-onset CVD, $n(\%)$ & $133(29.8)$ & \\
Smoking, $n(\%)$ & $72(16.1)$ & \\
Diabetes, $n(\%)$ & $250(55.9)$ & \\
Antidiabetic medication, $n(\%)$ & $180(72.0)$ & \\
Hyperlipidemia, $n(\%)$ & $322(72.0)$ & \\
Lipid-lowering agents, $n(\%)$ & $218(67.7)$ & \\
Hypertension, $n(\%)$ & $336(75.2)$ & \\
Antihypertensive medication, $n(\%)$ & $296(88.1)$ & \\
APOE 4 genotype, $n(\%) \dagger$ & $79(17.8)$ & \\
Serum C-reactive protein $(\mathrm{mg} / \mathrm{l})$ & 0.48 & $(0.01-9.95)$ \\
Total polyphenol excretion & & \\
$\quad$ (mg GAE/g Cr) & & \\
\hline
\end{tabular}

*Median. ${ }^{\dagger}$ Sum of E4/3 and E4/4 genotypes (E2/4 excluded). ${ }^{\ddagger} \mathrm{GAE} / \mathrm{g} \mathrm{Cr}$, gallic acid equivalents (GAE)/g of creatinine. Abbreviations: MET-min, minutes at a given metabolic equivalent level (units of energy expenditure in physical activity, 1 MET-min roughly equivalent to $1 \mathrm{Kcal}$ ); $\mathrm{CVD}$, cardiovascular disease; APOE, apolipoprotein E.

Table 2

Daily intake of energy and food groups of the study population $(n=447)$

\begin{tabular}{lcc}
\hline Variables & Mean or median & Range \\
\hline Total energy $(\mathrm{Kcal} / \mathrm{d})$ & 2362 & $(1066-3898)$ \\
Cereals/grains $(\mathrm{g} / \mathrm{d})$ & 252 & $(0-704)$ \\
Vegetables $(\mathrm{g} / \mathrm{d})$ & 406 & $(0-1480)$ \\
Legumes $(\mathrm{g} / \mathrm{d})$ & 19 & $(0-103)$ \\
Fruits $(\mathrm{g} / \mathrm{d})$ & 470 & $(0-1190)$ \\
Total nuts $(\mathrm{g} / \mathrm{d})$ & 5.13 & $(0-60)$ \\
Walnuts $(\mathrm{g} / \mathrm{d})$ & 1.10 & $(0-30)$ \\
Meat and meat products $(\mathrm{g} / \mathrm{d})$ & 89 & $(2-229)$ \\
Fish and seafood $(\mathrm{g} / \mathrm{d})$ & 114 & $(7-427)$ \\
Dairy products $(\mathrm{g} / \mathrm{d})$ & 359 & $(0-1367)$ \\
Total olive oil $(\mathrm{ml} / \mathrm{d})$ & 38 & $(0-75)$ \\
Virgin olive oil $(\mathrm{ml} / \mathrm{d})$ & $4 *$ & $(0-70)$ \\
Total alcohol $(\mathrm{g} / \mathrm{d})$ & $4^{*}$ & $(0-92)$ \\
Wine $(\mathrm{ml} / \mathrm{d})$ & $21^{*}$ & $(0-702)$ \\
Coffee $(\mathrm{ml} / \mathrm{d})$ & $21^{*}$ & $(0-350)$ \\
\hline
\end{tabular}

*Median.

mance. In the immediate recall of RAVLT, older age and cereal intake were associated with lower scores. Conversely, higher education years, the female gender, and higher intake of total olive oil were associated with immediate verbal memory. Intake of coffee and 
Table 3

Independent associations of cognitive test scores with food intake by multiple linear regression

\begin{tabular}{|c|c|c|c|c|}
\hline Neuropsychological test & Independent variables & $\begin{array}{c}\text { Regression coefficient } \\
(95 \% \text { confidence interval) }\end{array}$ & $\beta^{*}$ & $p$ \\
\hline \multirow[t]{5}{*}{ MMSE } & Wine per $200 \mathrm{ml} / \mathrm{d}$ & $0.252(0.006$ to 0.496$)$ & 0.096 & 0.044 \\
\hline & Age per 10 years & $-0.405(-0.624$ to -0.186$)$ & -0.170 & $<0.001$ \\
\hline & Education per 5 years & $0.529(0.324$ to 0.734$)$ & 0.238 & $<0.001$ \\
\hline & Diabetes & $-0.289(-0.553$ to -0.025$)$ & -0.104 & 0.032 \\
\hline & Hypertension & $-0.419(-0.717$ to -0.121$)$ & -0.132 & 0.006 \\
\hline RAVLT & Total olive oil per $10 \mathrm{~g} / \mathrm{d}$ & $0.755(0.151$ to 1.358$)$ & 0.109 & 0.014 \\
\hline \multirow[t]{4}{*}{ (immediate recall) } & Cereals per $40 \mathrm{~g} / \mathrm{d}$ & $-0.431(-0.823$ to -0.038$)$ & -0.098 & 0.032 \\
\hline & Age per 10 years & $-5.079(-6.454$ to -3.704$)$ & -0.329 & $<0.001$ \\
\hline & Gender (women) & $2.549(0.932$ to 4.165$)$ & 0.142 & 0.002 \\
\hline & Education per 5 years & $3.304(2.045$ to 4.562$)$ & 0.231 & $<0.001$ \\
\hline \multirow[t]{8}{*}{ RAVLT (delayed recall) } & Virgin olive oil per $10 \mathrm{~g} / \mathrm{d}$ & $0.163(0.010$ to 0.316$)$ & 0.094 & 0.037 \\
\hline & Coffee $(50 \mathrm{ml} / \mathrm{d})$ & $0.294(0.055$ to 0.534$)$ & 0.106 & 0.016 \\
\hline & Cereals per $40 \mathrm{~g} / \mathrm{d}$ & $-0.235(-0.379$ to -0.091$)$ & -0.149 & 0.001 \\
\hline & Meat per $100 \mathrm{~g} / \mathrm{d}$ & $-0.845(-1.556$ to -0.135$)$ & -0.109 & 0.020 \\
\hline & Age per 10 years & $-1.606(-2.108$ to -1.105$)$ & -0.288 & $<0.001$ \\
\hline & Gender (women) & $1.443(0.814$ to 2.072$)$ & 0.223 & $<0.001$ \\
\hline & Education per 5 years & $0.838(0.372$ to 1.304$)$ & 0.162 & $<0.001$ \\
\hline & Hypertension & $-0.735(-1.411$ to -0.059$)$ & -0.098 & 0.033 \\
\hline \multirow[t]{3}{*}{ Digit span (reverse) } & Walnuts per $30 \mathrm{~g} / \mathrm{d}$ & $1.191(0.061$ to 2.322$)$ & 0.149 & 0.039 \\
\hline & Education per 5 years & $0.365(0.126$ to 0.603$)$ & 0.220 & 0.003 \\
\hline & $\begin{array}{l}\text { Energy expenditure in physical } \\
\text { activity per } 100 \text { MET-min/d }\end{array}$ & $-0.103(-0.155$ to -0.051$)$ & -0.286 & $<0.001$ \\
\hline
\end{tabular}

Cognitive test scores are the dependent variables. The independent variables listed are those showing $p<0.05$ after regression analyses. * $\beta$ : Standardized regression coefficient. Abbreviations: MMSE, Mini Mental State Examination; RAVLT, Rey Auditory Verbal Learning Test; MET-min, minutes at a given metabolic equivalent level. Variables allowed into the models were gender, age, education, body mass index, smoking, APOE $\varepsilon 4$ allele, energy expenditure in physical activity, diabetes, hypertension, and hyperlipidemia.

VOO, higher education years, and the female gender were associated with better performance in the delayed recall of RAVLT, while older age, hypertension, and intake of cereals and meat were associated with lower scores. Total olive oil intake was also independently associated with the delayed recall of RAVLT (regression coefficient $0.36, p=0.001$ ), but only data on VOO is shown in Table 3 because of the novelty of the finding. The consumption of walnuts was also associated with better working memory, as assessed by the reverse digit span test of the WAIS battery.

Total urinary polyphenol excretion was significantly and independently associated with the immediate recall score of RAVLT and nearly significantly with the delayed recall of RAVLT (Table 4), but not with the other neuropsychological test. Female gender and higher education years (directly) and age and diabetes (inversely) also related independently to RALVT scores. Figure 2 shows that there was a dose-relationship between urinary polyphenols and enhancement of the RAVLT score. Moreover, after adjusting by gender, age, and BMI, we found a significant albeit weak inverse correlation between the logarithmically transformed values of total urinary polyphenol excretion and CRP $(r=-0.102$, $p=0.044)$.

\section{DISCUSSION}

In this cross-sectional evaluation of dietary habits and cognitive function in older persons at high cardiovascular risk living in a Mediterranean country, higher intakes of both total olive oil and the virgin variety of olive oil, coffee, walnuts, and wine were associated with better memory function and global cognition. The magnitude of these associations was variable and they were present in some but not in all tests of cognitive function, but were independent of known cognition-related confounders and consumption of other food groups. The findings on VOO and walnuts, two foods with high antioxidant capacity [40, 41], are novel. Another novel finding is the independent association of total urinary polyphenol excretion, an objective biomarker of polyphenol-rich food intake, with human memory function. Taken together, these results suggest that antioxidants in the usual diet might counteract age-related cognitive decline [6]. 
Table 4

Independent associations of cognitive test scores with urinary polyphenols excretion by multiple linear regression analysis

\begin{tabular}{|c|c|c|c|c|}
\hline Neuropsychological test & Independent variables & $\begin{array}{l}\text { Regression coefficient } \\
\text { (95\% confidence interval) }\end{array}$ & $\beta^{*}$ & $p$ \\
\hline \multirow[t]{5}{*}{ RAVLT (immediate recall) } & Polyphenol excretion per $100 \mathrm{mg}$ GAE/g Cr & $1.208(0.236$ to 2.180$)$ & 0.112 & 0.015 \\
\hline & Age per 10 years & $-5.547(-6.987$ to -4.106$)$ & -0.351 & $<0.001$ \\
\hline & Gender (women) & $2.436(0.637$ to 4.234$)$ & 0.133 & 0.008 \\
\hline & Education per 5 years & $3.734(2.423$ to 5.045$)$ & 0.258 & $<0.001$ \\
\hline & Diabetes & $-1.719(-3.419$ to -0.018$)$ & -0.094 & 0.048 \\
\hline \multirow[t]{5}{*}{ RAVLT (delayed recall) } & Polyphenol excretion per $100 \mathrm{mg}$ GAE/g Cr & $0.357(-0.004$ to 0.719$)$ & 0.092 & 0.053 \\
\hline & Age per 10 years & $-1.673(-2.209$ to -1.137$)$ & -0.295 & $<0.001$ \\
\hline & Gender (women) & $1.343(0.673$ to 2.012$)$ & 0.205 & $<0.001$ \\
\hline & Education per 5 years & $1.037(0.549$ to 1.525$)$ & 0.200 & $<0.001$ \\
\hline & Diabetes & $-0.621(-1.254$ to 0.112$)$ & -0.095 & 0.054 \\
\hline
\end{tabular}

Cognitive test scores are the dependent variables. The independent variables listed are those showing $P$ values close to $<0.05$ after regression analyses. * $\beta$ : Standardized regression coefficient. Abbreviations: RAVLT, Rey Auditory Verbal Learning Test; GAE/g Cr, gallic acid equivalents/g of creatinine. Variables allowed in the models were gender, age, education, body mass index, energy intake (Kcal/day), smoking, APOE $\varepsilon 4$ allele, energy expenditure in physical activity, diabetes, hypertension, and hyperlipidemia.
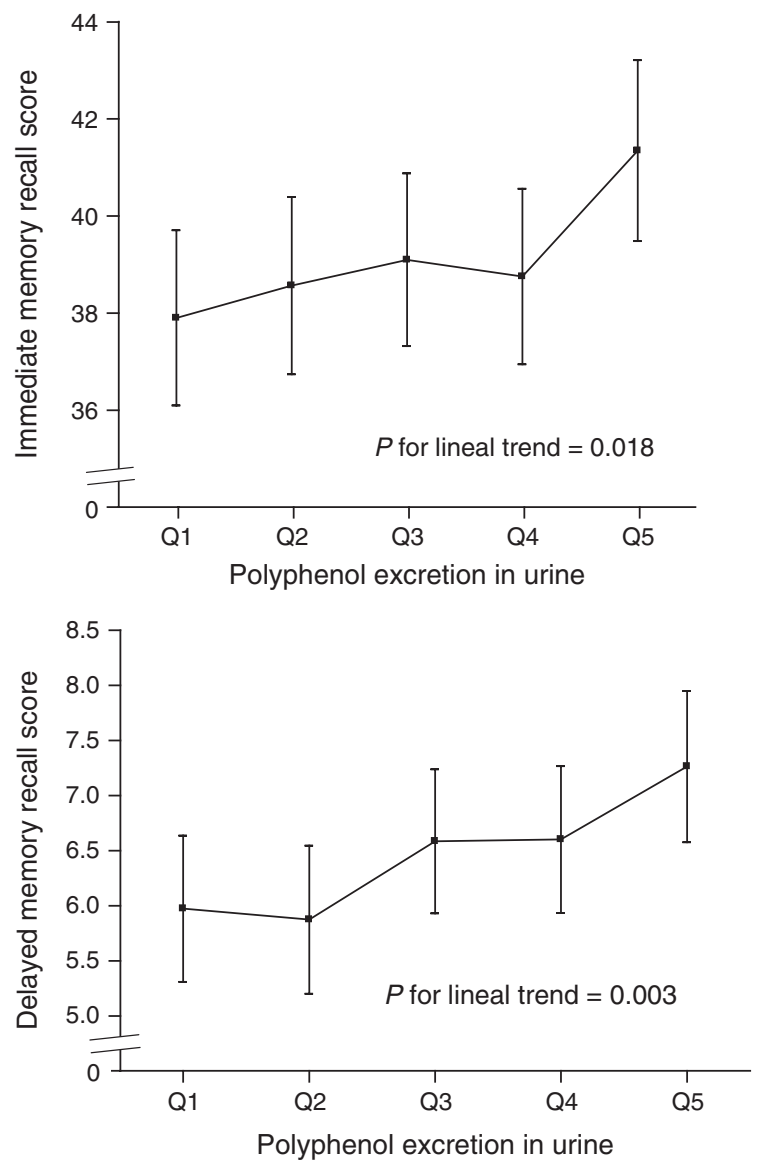

Fig. 2. RAVLT scores across quintiles of urinary polyphenol excretion.

Olive oil is a major component of the traditional Mediterranean diet. It contains abundant monounsaturated fatty acids (MUFA), mostly oleic acid, and, depending on the degree of refinement, variable proportions of bioactive micronutrients, such as phytosterols, vitamin E, and phenolic compounds [40]. Because of a lower cost, common olive oil (a mixture of refined oil with a small proportion of VOO) is widely used in Spain in the kitchen and at the table, while VOO, which is obtained by cold pressing of the ripe fruit and is much richer in minor but bioactive components, has a more restricted consumption, as shown in our study group (Table 2). Greater consumption of VOO in the Mediterranean diet has been associated with various health benefits [40]. Few epidemiological studies have related consumption of MUFA with cognitive function. MUFA is contained in other foods, for example beef, besides olive oil. This heterogeneity in the dietary sources of MUFA might explain why some results are inconsistent [42-46]. Recently, in line with our results, a weak association of total olive oil intake with a reduced risk of cognitive impairment was reported in a large French cohort [47].

We found that increasing consumption of walnuts, but not of other nuts, was associated with better working memory scores. Interestingly, walnuts are among the foods with highest antioxidant capacity, by far surpassing other nuts [48]. They are also the whole food richest in $\alpha$-linolenic acid, the vegetable n-3 fatty acid [41]. Consistent evidence from prospective studies suggests that frequent nut intake relates to lower CHD rates [49]. This may be due in part to the beneficial effects of nuts on blood lipids [50] and other disease biomarkers, including oxidation, inflammation, and endothelial dysfunction [41]. Furthermore, higher intake of nuts has been related with better cognitive function and lesser cognitive decline in a prospective study [51]. Our findings, together with those of a recent experimental study showing that walnut supplementation improves both motor and cognitive function in 
aged rats [52], point to the need for further studies on nuts and cognition.

There is consistent epidemiological evidence that moderate consumption of alcohol relates inversely to risk of CHD and total mortality [53]. Among alcoholic beverages, wine possibly provides additional cardiovascular benefits because it counteracts oxidative stress through its high polyphenolic content [54]. In our study participants who consumed alcohol were mostly moderate wine drinkers, and the daily dose of wine related to a better overall cognitive function in them. These findings concur with the results of other studies showing an association of moderate alcohol consumption with better cognitive performance and a reduced risk of neurodegenerative diseases [55, 56].

Because coffee, a beverage with high antioxidant content, is commonly consumed in European Mediterranean countries, we assessed its association with cognitive performance. The observed direct association with verbal memory is consistent with prior evidence on the protective effect of caffeine against development of AD [57].

A common characteristic of the foods directly related to cognitive performance in our study is their richness in polyphenols, highly bioactive molecules with beneficial effects that go beyond the modulation of oxidative stress to improve brain function, at least in experimental models of aging [58]. Indeed, urinary polyphenol excretion was independently associated with memory performance with a continuous, dose-related effect. These findings, heretofore not described, support the validity of the observed associations among antioxidant-rich foods and cognition. Antioxidant-rich foods, but not total polyphenol excretion, have been related to better cognitive performance also in other clinical studies [6, 26, 59-61]. Furthermore, animals fed antioxidant foods showed improved cellular signaling and neuronal communication that translated into better cognitive and motor performance [52, 58, 63]. A chronic inflammatory state promoted by oxidative stress is an integral part of neurodegenerative diseases. The inverse correlation between urinary polyphenols and serum CRP observed in our study is an additional argument in favor of antioxidant-rich foods. Our results further support the general theory of oxidative stress as a major driving force for age-related neurodegenerative processes [53].

Other variables independently associated with cognitive function in our study, such as gender, age, education years, diabetes, hypertension, and meat intake showed relationships in the expected direction $[3,5]$, except for those concerning cereal intake and physical activity. That cereal intake related inversely to memory function might be due to the fact that little amounts of whole grains are consumed in Spain. Refined grains have a high glycemic index that is associated with insulin resistance, a covariate of cognitive dysfunction [5]. The inverse association between physical activity and verbal memory was unexpected and is difficult to explain. Given the crosssectional design of our study, it might be explained by reverse causation if participants at higher vascular risk, hence more prone to develop impaired cognition, exercised more following advice of their caretakers.

Our study has limitations. First, the sample size is relatively small. Second, given the cross-sectional design of the study, we cannot exclude the possibility of reverse causation or residual confounding. Third, the neuropsychological test battery used does not include all cognitive functions, although verbal memory, one of the first areas to be affected with aging, was well assessed with RAVLT and WMS associated pairs. Finally, our cohort was at a particularly high vascular risk, thus the results may not be generalized to the average elderly population. The study also has strengths, such as the wide between-subject variability of food consumption, a comprehensive evaluation of cardiovascular risk and dietary intake and, in particular, the use of urinary polyphenols as an objective biomarker of intake that is not subject to the possibilities of bias or inaccurate reporting.

In conclusion, in the context of the Mediterranean diet, increasing consumption of antioxidant-rich foods in general and of polyphenols in particular is associated with better cognitive performance in an elderly cohort at high cardiovascular risk. The results reinforce the notion that Mediterranean diet components might counteract age-related cognitive decline $[19,21-23]$. While causality cannot be inferred from results of a cross-sectional assessment such as the present one, antioxidant-rich foods are known for many beneficial properties with no harm, thus they can be recommended to the general public to promote better health, including probably better cognitive function. The prospective examination of the whole cohort of the 6-year PREDIMED trial will eventually provide firmer evidence regarding the potential of the Mediterranean diet to counteract the effects of aging on cognitive decline and reduce the incidence of neurodegenerative diseases, including AD. 


\section{ACKNOWLEDGMENTS}

We thank the PREDIMED participants for their willingness and enthusiasm to collaborate in the study and Emili Corbella for providing expert assistance with statistical analyses. CIBERobn and RETIC RD06/0045 are initiatives of ISCIII, Spain. This study was supported by PI07-0954 from ISCIII and GVACOMP2010-181 from Generalitat Valenciana (Prof Corella); AGL2010-22319-C03-01/02/03 (Drs Lamuela-Raventós and Medina-Remón); FIS PI 07/0473 and AGL2007-66638-C02-01/02 (Dr Estruch); PI070240, PI070312, and PI081943 from ISCIII (Prof Martínez-González).

Authors' disclosures available online (http://www.jalz.com/disclosures/view.php?id=1126).

\section{REFERENCES}

[1] Ritchie K, Lovestone S (2002) The dementias. Lancet 360, 1759-1766.

[2] Hedden T, Gabrieli JDE (2004) Insights into the ageing mind: A view from cognitive neuroscience. Nat Rev Neurosci 5 , 87-96.

[3] Flicker L (2010) Modifiable lifestyle risk factors for Alzheimer's disease. J Alzheimers Dis 20, 803-811.

[4] Stern Y (2002) What is cognitive reserve? Theory and research application of the reserve concept. J Int Neuropsychol Soc 8, 448-460.

[5] Gómez-Pinilla F (2008) Brain foods. The effects of nutrients on brain function. Nat Rev Neurosci 9, 568-578.

[6] Gillette Guyonnet S, Abellan Van Kan G, Andrieu S, Barberger-Gateau P, Berr C, Bonnefoy M, Dartigues JF, De Groot L, Ferry M, Galan P, Hercberg S, Jeandel C, Morris MC, Nourhashemi F, Payette H, Poulaine JP, Portet F, Roussel AM, Ritz P, Rolland Y, Vellas B (2007) IANA task force on nutrition and cognitive decline with aging. J Nutr Health Aging 11, 132-152.

[7] Polidori MC, Pratico D, Mangialasche F, Mariani E, Aust O, Anlasik T, Mang N, Pientka L, Stahl W, Sies H, Mococci P, Nelles G (2009) High fruit intake is positively correlated with antioxidant status and cognitive performance in healthy subjects. J Alzheimers Dis 17, 921-927.

[8] Muldoon MF, Ryan CM, Sheu L, Yao JK, Conklin SM, Manuck SB (2010) Serum phospholipid docosahexaenonic acid is associated with cognitive functioning during middle adulthood. J Nutr 140, 848-853.

[9] Roberts RO, Cerhan JR, Geda YE, Knopman DS, Cha RH, Christianson TJH, Pankratz VS, Ivnik Rj, O'Connor HM, Petersen RC (2010) Polyunsaturated fatty acids and reduced odds of MCI: The Mayo Clinic Study of Aging. J Alzheimers Dis 21, 853-865.

[10] Mangialasche F, Kivipelto M, Mecocci P, Rizzuto D, Palmer K, Winblad B, Fratiglioni L (2010) High plasma levels of vitamin E forms and reduced Alzheimer's disease risk in advanced age. J Alzheimers Dis 20, 1029-1037.

[11] Jacobs DR Jr, Gross MD, Tapsell LC (2009) Food synergy: An operational concept for understanding nutrition. Am J Clin Nutr 89, 1543S-1548S.
[12] Gu Y, Nieves JW, Stern Y, Luchsinger JA, Scarmeas N (2010) Food combination and Alzheimer disease risk. A protective diet. Arch Neurol 67, 699-706.

[13] Serra-Majem L, Roman B, Estruch R (2006) Scientific evidence of interventions using the Mediterranean diet: A systematic review. Nutr Rev 64, S27-S47.

[14] Mente A, de Koning L, Shannon HS, Anand SS (2009) A systematic review of the evidence supporting a causal link between dietary factors and coronary heart disease. Arch Intern Med 169, 659-669.

[15] Martínez-González MA, García-López M, Bes-Rastrollo M, Toledo E, Martínez-Lapiscina EH, Delgado-Rodríguez M, Vázquez Z, Benito S, Beunza JJ (2011) Mediterranean diet and the incidence of cardiovascular disease: A Spanish cohort. Nutr Metab Cardiovasc Dis 21, 237-244.

[16] Sofi F, Abbate R, Gensini GF, Casini A (2010) Accruing evidence about benefits of adherence to the Mediterranean diet on health: An updated systematic review and meta-analysis. Am J Clin Nutr 92, 1189-1196.

[17] Feart C, Samieri C, Barberger-Gateau P (2010) Mediterranean diet and cognitive function in older adults. Curr Opin Clin Nutr Metab Care 13, 14-18.

[18] Tangney CC, Kwasny MJ, Li H, Wilson RS, Evans DA, Morris MC (2011) Adherence to a Mediterranean-type dietary pattern and cognitive decline in a community population. Am J Clin Nutr 93, 601-607.

[19] Scarmeas N, Stern Y, Mayeux R, Manly JJ, Schupf N, Luchsinger JA (2009) Mediterranean diet and mild cognitive impairment. Arch Neurol 66, 216-225.

[20] Gao X, Chen HL, Fung TT, et al. (2007) Prospective study of dietary pattern and risk of Parkinson disease. Am J Clin Nutr 86, 1486-1494.

[21] Scarmeas N, Stern Y, Mayeux R, Luchsinger JA (2006) Mediterranean diet, Alzheimer disease, and vascular mediation. Arch Neurol 63, 1709-1717.

[22] Feart C, Sanieri C, Rondeau V, Amieva H, Portet F, Dartigues JF, Scarmeas N, Barberger-Gateau P (2009) Adherence to a Mediterranean diet, cognitive decline and risk of dementia. JAMA 302, 638-648.

[23] Scarmeas N, Luchsinger JA, Mayeux R, Stern Y (2007) Mediterranean diet and Alzheimer disease mortality. Neurology 69, 1084-1093.

[24] Frisardi V, Panza F, Seripa D, Imbimbo BP, Vendemiale G, Pilotto A, Solfrizzi V (2010) Nutraceutical properties of Mediterranean diet and cognitive decline: Possible underlying mechanisms. J Alzheimers Dis 22, 715-740.

[25] Steele M, Stuchbury G, Münch G (2007) The molecular basis of the prevention of Alzheimer's disease through healthy nutrition. Exp Gerontol 42, 28-36.

[26] Letenneur L, Proust-Lima C, Le Gouge A, Dartigues JF, Barberger-Gateau P (2007) Flavonoid intake and cognitive decline over a 10-year period. Am J Epidemiol 165, 13641371.

[27] Martínez-González MA, Corella D, Salas-Salvadó J, Ros E, Covas MI, Fiol M, Wärnberg J, Aros F, RuízGutiérrez V, Lamuela-Raventós RM, Lapetra J, Muñoz MA, Martínez JA, Sáez G, Serra-Majem L, Pintó X, Mitjavila MT, Tur JA, Portillo MD, Estruch R, for the PREDIMED Study Investigators (2010) Cohort Profile: Design and methods of the PREDIMED study. Int J Epidemiol, doi:10.1093/ije/dyq250.

[28] Elosua R, Marrugat J, Molina L, Pons S, Pujol E (1994) Validation of the Minnesota Leisure Time Physical Activity Questionnaire in Spanish men. The MARATHOM Investigators. Am J Epidemiol 139, 1197-1209. 
[29] Fernández-Ballart JD, Piñol JL, Zazpe I, Corella D, Carrasco P, Toledo E, Pérez-Bauer M, Martínez-González MA, Salas-Salvadó J, Martín-Moreno JM (2010) Relative validity of a semi-quantitative food-frequency questionnaire in an elderly Mediterranean population of Spain. Br J Nutr 103, 1808-1816.

[30] Hixson JE, Vernier DT (1990) Restriction isotyping of human apolipoprotein $\mathrm{E}$ by gene amplification and cleavage with Hhal. J Lipid Res 31, 545-548.

[31] Medina-Remón A, Barrionuevo-González A, Zamora-Ros R, Andrés-Lacueva C, Estruch R, Martínez-González MA, Díez-Espino J, Lamuela-Raventós RM (2009) Rapid FolinCiocalteu method using microtiter 96-well plate cartridges for solid phase extraction to assess urinary total phenolic compounds as a biomarker of total polyphenol intake. Anal Chim Acta 634, 54-60.

[32] Zamora-Ros R, Rabassa M, Cherubini A, Urpi-Sarda M, Llorach R, Bandinelli S, Ferrucci L, Andres-Lacueva C (2011) Comparison of 24-h volume and creatinine-corrected total urinary polyphenol as a biomarker of total dietary polyphenols in the Invecchiare In CHIANTI study. Anal Chim Acta 704, 110-115.

[33] Hamilton M (1967) Development of a rating scale for primary depressive illness. Br J Soc Clin Psychol 6, 278-296.

[34] Folstein MF, Folstein SE, McHugh PR (1975) "Mini-mental state". A practical method for grading the cognitive state of patients for the clinician. J Psychiatr Res 12,189-198.

[35] Rey A (1964) L'examen Clinique en Psychologie, Presses Universitaires de France, Paris.

[36] Wechsler D (1945) A standardized memory scale for clinical use. J Psychol 19, 87-95.

[37] Ramier AM, Hecaen H (1970) Rôle respectif des atteintes frontales et de la latéralisation lésionnelle dans les déficits de la fluence verbale. Rev Neur 123, 17-22.

[38] Wechsler D (1999) Escala de inteligencia de Wechsler para adultos-III (WAIS III), TEA Ediciones, Madrid.

[39] D'Elia LF, Satz P, Uchiyama CL, White T (1994) Color Trails: Professional manual, Psychological assessment resources, Odessa (Florida)

[40] Lopez-Miranda J, Perez-Jimenez F, Ros E, De Caterina R, Badimon L, Covas MI, Escrich E, Ordovas JM, Soriguer F, Abia R, de la Lastra CA, Battino M, Corella D, Chamorro-Quiros J, Delgado-Lista J, Giugliano D, Esposito K, Estruch R, Fernandez-Real JM, Gaforio JJ, La Vecchia C, Lairon D, Lopez-Segura F, Mata P, Menendez JA, Muriana FJ, Osada J, Panagiotakos DB, Paniagua JA, Perez-Martinez P, Perona J, Peinado MA, Pineda-Priego M, Poulsen HE, Quiles JL, Ramirez-Tortosa MC, Ruano J, Serra-Majem L, Sola R, Solanas M, Solfrizzi V, de la Torre-Fornell R, Trichopoulou A, Uceda M, Villalba-Montoro JM, Villar-Ortiz JR, Visioli F, Yiannakouris N (2010) Olive oil and health: Summary of the II International Conference on Olive Oil and Health consensus report, Jaén and Córdoba (Spain) 2008. Nutr Metab Cardiovasc Dis 20, 284294.

[41] Ros E (2009) Nuts and novel biomarkers of cardiovascular disease. Am J Clin Nutr 89, S1649-S1656.

[42] Ortega RM, Requejo AM, Andres P, López-Sobaler AM, Quintas ME, Redondo MR, Navia B, Rivas T (1997) Dietary intake and cognitive function in a group of elderly people. Am J Clin Nutr 66, 803-809.

[43] Solfrizzi V, Panza F, Torres F, Mastroianni F, Del Parigi A, Venezia A, Capurso A (1999) High monounsaturated fatty acid intake protects against age-related cognitive decline. Neurology 52, 1563-1569.
[44] Solfrizzi V, Colacicco AM, D'Introno A, Capurso C, Del Parigi A, Capurso SA, Argentieri G, Capurso A, Panza F (2006) Dietary fatty acids intakes and rate of mild cognitive impairment. The Italian Longitudinal Study on Aging. Exp Gerontol 41, 619-627.

[45] Psaltopoulou T, Kyrozis A, Stathopoulos P, Trichopoulos D, Vassilopoulos D, Trichopoulou A (2008) Diet, physical activity and cognitive impairment among elders: The EPIC-Greece cohort (European Prospective Investigation in Cancer and Nutrition). Public Health Nutr 11, 1054-1062.

[46] Cherbuin N, Astey KJ (2011) The Mediterranean diet is not related to cognitive change in a large prospective investigation: The PATH Through Life Study. Am J Geriatr Psychiatry, doi:10.1097/JGP.0b013e31823032a9.

[47] Berr C, Portet F, Carriere I, Akbaraly TN, Feart C, Gourlet V, Combe N, Barberger-Gateau P, Ritchie K (2009) Olive oil and cognition: Results from the Three-City study. Dement Geriatr Cogn Disord 28, 357-364.

[48] Halvorsen BL, Holte K, Myhrstad MC, Barikmo I, Hvattum E, Remberg SF, Wold AB, Haffner K, Baugerod H, Andersen LF, Moskaug JO, Jacobs DR, Blomhoff R (2002) A systematic screening of total antioxidants in dietary plants. J Nutr 132, 461-471.

[49] Kelly JH Jr, Sabaté J (2006) Nuts and coronary heart disease, an epidemiological perspective. Br J Nutr 96, S61-S67.

[50] Sabaté J, Oda K, Ros E (2010) Nut consumption and blood lipid levels. A pooled analysis of 25 intervention trials. Arch Intern Med 170, 821-827.

[51] Nooyens ACJ, Bueno-de-Mesquita HB, van Boxtel MPJ, van Gelder BM, Verhagen H, Verschuren WMM (2011) Fruit and vegetable intake and cognitive decline in middle-aged men and women: The Doetinchem Cohort Study. Br J Nutr 106, 752-761.

[52] Willis LM, Shukitt-Hale B, Cheng V, Joseph JA (2009) Dosedependent effects of walnuts on motor and cognitive function in aged rats. Br J Nutr 101, 1140-1144.

[53] Ronksley PE, Brien SE, Turner BJ, Mukamal KJ, Ghali WA (2011) Association of alcohol consumption with selected cardiovascular diseases outcomes: A systematic review and meta-analysis. BMJ 342, d671.

[54] Covas MI, Gambert P, Fitó M, de la Torre R (2010) Wine and oxidative stress: Up-to-date evidence of the effects of moderate wine consumption on oxidative damage in humans. Atherosclerosis 208, 297-304.

[55] Peters R, Peters J, Warner J, Beckett N, Bulpitt C (2008) Alcohol, dementia and cognitive decline in the elderly: A systematic review. Age Ageing 37, 505-512.

[56] Panza F, Capurso C, D'Introno A, Colacicco AM, Frisardi V, Lorusso M, Santamato A, Seripa D, Pilotto A, Scafato E, Vendemiale G, Capurso A, Solfrizzi V (2009) Alcohol drinking, cognitive functions in older age, predementia, and dementia syndromes. J Alzheimers Dis 17, 7-31.

[57] Eskelinen MH, Kivipelto M (2010) Caffeine as a protective factor in dementia and Alzheimer's disease. J Alzheimers Dis 20, 167-174.

[58] Joseph JA, Shukitt-Hale B, Casadesus G (2005) Reversing the deleterious effects of aging on neuronal communication and behavior: Beneficial properties of fruit polyphenolic compounds. Am J Clin Nutr 81, 313S-316S.

[59] Esposito E, Rotilio D, Di Mateo V, Di Giulio C, Cacchio M, Algeri S (2002) A review of specific dietary antioxidants and the effects on biochemical mechanisms related to neurodegenerative processes. Neurobiol Aging 23, 719-735.

[60] Kesse-Guyot E, Fezeu L, Jeandel C, Ferry M, Andreeva V, Amieva H, Hercberg S, Galan P (2011) French adults' cogni- 
tive performance after daily supplementation with antioxidant vitamins and minerals at nutritional doses: A post hoc analysis of the Supplementation in Vitamins and Mineral Antioxidants (SU.VI.MAX) trial. Am J Clin Nutr 94, 892-899.

[61] Krikorian R, Nash TA, Shidler MD, Shukitt-Hale B, Joseph JA (2010) Concord grape juice supplementation improves memory function in older adults with mild cognitive impairment. Br J Nutr 103, 730-734.
[62] Droge W, Schipper HM (2007) Oxidative stress and aberrant signalling in aging and cognitive decline. Aging Cell 6, 361370.

[63] Joseph JA, Cole G, Head E, Ingram D (2009) Nutrition, brain aging, and neurodegeneration. J Neurosci 29, 12795-12801. 